services that offer cordotomy to provide relief from pain. There is however, great inequity in the provision of services offering cordotomy; the level of evidence to support the provision of invasive neuro-destructive procedures such as cordotomy is poor. For this small group of patients the procedures may yield significant analgesic benefit, however there is an as yet unquantified associated morbidity. This is a pilot study that focuses on cordotomy.

Aims and Methods To establish consensus on the role of cordotomy in mesothelioma related pain and to set up a National Registry. We undertook a systematic review of the literature, and used a novel web based consensus methodology approach to clarify the role of cordotomy in the management of mesothelioma-related pain. We examined whether there was sufficient evidence to support continued provision and commissioning of cordotomy, and provide a benchmark for the availability and use of this procedure in the treatment of pain associated with mesothelioma in the U.K. The study culminated in a Consensus Conference at the Royal Society of Medicine on the 10th October 2011. Following this, we will establish a national registry study for cordotomy in mesothelioma-related pain management with Dendrite Clinical Systems.

Results The results of the systematic review and web based consensus work will be presented. 101 participants completed the web based questionnaire; there were two rounds of Delphi before consensus was reached. Availability of cordotomy in the U.K. will be discussed.

Conclusion The approach of systematic review, Web Based Delphi, Nominal Group and Consensus Conference was successful. In view of this we plan to apply the methodology to other interventional approaches in palliative and supportive care. A surprise finding was the quantity of qualitative data that came through the web based consensus tool.

\title{
OP 02 THE RESULTS OF THE INVASIVE NEURODESTRUCTIVE PROCEDURES IN CANCER PAIN PILOT STUDY (INPIC) WHAT IS THE ROLE OF CORDOTOMY IN PAIN ASSOCIATED WITH MALIGNANT MESOTHELIOMA?
}

M. Makin ${ }^{1,2^{*}}$, J. Ellershaw ${ }^{2,4}$, A. Leach ${ }^{4,7}$, M. Poolman', M. Sharma ${ }^{3}$, G. Jeffers ${ }^{6}$, J. Bridson ${ }^{4,7}{ }^{1}$ Betsi Cadwaladr University Health Board, North Wales; ${ }^{2}$ Marie Curie Palliative Care Institute, Liverpool; 'Walton Centre for Neurology and Neurosurgery, Liverpool; ${ }^{4}$ Royal Liverpool University Hospitals, Liverpool; ${ }^{5}$ Liverpool Cancer Trials Unit, Liverpool; ${ }^{6}$ Cardiff University, Wales; ${ }^{7}$ National Refractory Angina Centre, Liverpool

10.1136/bmjspcare-2012-000264.2

Introduction There are around 1800 new cases of mesothelioma annually in the UK.The incidence of mesothelioma is still rising and is expected to peak between 2010 and 2015. Symptom control is central to the management of patients with mesothelioma. The National Mesothelioma Framework (2007) has suggested that patients should have access to 